\title{
CA 19.9 na Coledocolitíase: Caso Clínico
}

\section{CA 19.9 in Choledocholithiasis: Case Report}

\author{
Paulo Costa Correia ${ }^{1}$, Maria Luís Santos², Francisco O. Vieira ${ }^{2}$
}

\section{RESUMO}

Com base num paciente com elevação acentuada dos níveis de CA 19.9 sérico, portador de coledocolitíase, são feitas algumas considerações sobre a utilidade dos marcadores tumorais na prática clínica.

Um nível elevado deste antigénio nem sempre corresponde a patologia maligna, não sendo específico da mesma, retirando importância diagnóstica ao mesmo, muitas vezes, confundindo situações. Estudos retrospetivos demonstram que o uso indevido dos marcadores tumorais encarece os sistemas de saúde, deturpam e atrasam diagnósticos. No entanto, os autores reforçam o seu papel no acompanhamento de pacientes oncológicos, com diagnóstico comprovado de neoplasias, podendo ser benéficos para decisões terapêuticas futuras e vigilância clínica.

PALAVRAS-CHAVE: Antigénio CA-19-9; Biomarcadores Tumorais; Coledocolitíase/diagnóstico

\section{ABSTRACT}

Based on a patient with a marked increase in serum CA 19.9, with choledocholithiasis, some considerations are made about the usefulness of tumor markers in clinical practice.

A high level of this antigen does not always correspond to malignant pathology, it is not specific for it, withdrawing its diagnostic importance, often confusing situations. Retrospective studies show that the improper use of tumor markers makes health systems more expensive, it may confound and delay diagnosis.

However, the authors reinforce their role in monitoring cancer patients, with a proven diagnosis of neoplasms, which may be beneficial for future therapeutic decisions and clinical surveillance.

KEYWORDS: Biomarkers, Tumor; CA-19-9 Antigen; Choledocholithiasis/diagnosis

1.Assistente Graduado Sénior de Cirurgia Geral da ULS - GUARDA, Guarda, Portugal; Prof. Convidado da Faculdade de Ciências da Saúde da Universidade da Beira Interior (UBI), Covilhã, Portugal. 2. Interno de Formação Geral da ULS - GUARDA, Guarda, Portugal, Serviço de Cirurgia Geral do Hospital Sousa Martins - ULS Guarda, Guarda, Portugal.

Recebido/Received: 28/04/2020 - Aceite/Accepted: 25/08/2020 - Publicado online/Published online: 30/09/2020

• Autor (es) (ou seu (s) empregador (es)) e Gazeta Médica 2020. Reutilização permitida de acordo com CC BY-NC. Nenhuma reutilização comercial. ${ }^{\circledR}$ Author(s) (or their employer(s)) and Gazeta Médica 2020. Re-use permitted under CC BY-NC. No commercial re-use. 


\section{INTRODUÇÃO}

O antigénio carbohidratado (CA) 19.9 é um marcador tumoral que tem como objectivo principal o acompanhamento de pacientes com doenças pancreático-biliares malignas. Os níveis deste marcador podem estar elevados em patologias benignas com diferentes origens: biliar, ${ }^{1}(. .$.$) gastrointestinal { }^{2}$ ou urológica. ${ }^{3}$

Embora a especificidade de um nível de CA 19.9 $>1000 \mathrm{U} / \mathrm{mL}$ seja de $99 \%$ para cancro pancreático, ${ }^{4}$ existem certas patologias benignas que também podem provocar este tipo de elevação, nomeadamente, coledocolitíase, colangite, pancreatite aguda, diabetes e cirrose hepática.5,6

Em pacientes assintomáticos com CA 19.9 elevado, somente $2,8 \%$ são diagnosticados com doenças malignas, razão pela qual este antigénio não é recomendado como "screening".

Estudos recentes têm revelado dados alarmantes quanto a utilização indevida de marcadores tumorais como ferramenta clínica. Um estudo retrospetivo grego num hospital deste país, mostrou que menos de 10\% dos pedidos dos marcadores tumorais foram adequados, acarretando custos enormes, sem contar, com os gastos decorrentes de outros exames complementares solicitados inapropriadamente após um falso positivo. ${ }^{8}$

O CA 19.9 é produzido por vários tecidos do trato intestinal e glândulas anexas, nomeadamente pâncreas, fígado, intestino, epitélio biliar. Este antigénio, normalmente, é transportado pelos ductos biliar e pancreático até ao duodeno onde é descarregado, sendo muito raramente libertado para o sangue. Pode estar elevado nas doenças biliares benignas pelos seguintes mecanismos patogénicos ${ }^{9}$ :

- A pressão excessiva nos canais biliares estimula as células dos mesmos a produzir uma maior quantidade deste antigénio;

- A inflamação propicia a hiperplasia epitelial, dando origem à maior secreção do CA 19.9;

- A obstrução biliar e a consequente colestase diminuem a sua excreção biliar, aumentando a sua absorção e elevando os seus níveis séricos.

Logo que a inflamação é tratada e/ou a obstrução de natureza benigna é resolvida os níveis deste antigénio voltam ao normal.

\section{CASO CLÍNICO}

Em 12/02/2020, uma paciente de 61 anos foi admitida na Urgência com dor abdominal, que irradiava para a região lombar. Estava sub-ictérico. Como antecedentes clínicos relevantes apresentava um internamento por pancreatite aguda litiásica em 06/10/2019.

Exame físico: Hemodinamicamente estável. $\bigcirc$ abdómen apresentava-se mole e depressível, sem defesa, mas com dor à palpação profunda no ponto vesicular.

Resultados laboratoriais: leucócitos: $17,14 \times 10^{3} / \mu \mathrm{L}$; neutrófilos: $15,77 \times 10^{3} / \mu \mathrm{L}$ aspartato aminotransferase (AST): $213 \mathrm{U} / \mathrm{L}$; alanina aminotransferase (ALT): $251 \mathrm{U} / \mathrm{L}$; bilirrubina total: 2,40 mg/dL; bilirrubina direta: 1,81 mg/dL; Gama-GT (GGT): 664 U/L; fosfatase alcalina (FA): $255 \mathrm{U} / \mathrm{L}$; lactato desidrogenase (LDH): $308 \mathrm{U} / \mathrm{L}$.

Tomografia computorizada (TC) abdominal: "Dilatação das vias biliares intra-hepáticas (VBIH) e da via biliar principal (VBP) de $18 \mathrm{~mm}$, até ao segmento peri-pancreático/papila. Vesícula biliar em moderada repleção, com parede fina e sem sinais de litíase cálcica. Cálculo no colédoco? Adenomegálias hilares hepáticas e peri-pancreáticas. Fígado, pâncreas e baço sem alterações" (Fig. 1).
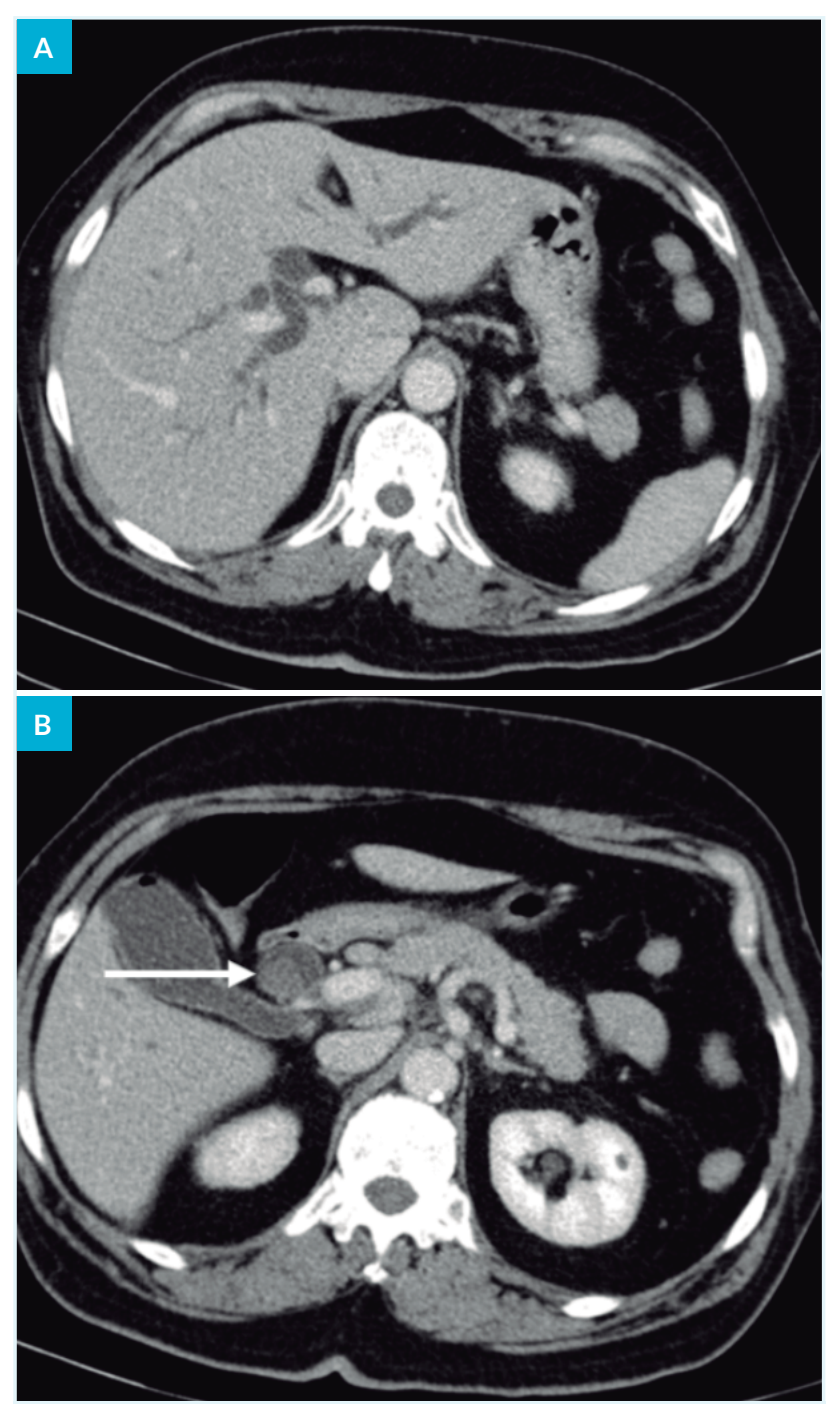

FIGURA 1. TC abdominal. A - Vias biliares intra-hepáticas dilatadas. B - Cálculo no interior do colédoco (?). 
A doente foi internada com uma colestase de natureza extra-hepática a esclarecer.

Cerca de 2 a 3 dias depois, a dor cedeu perante analgesia surgindo icterícia que se veio a acentuar nos dias subsequentes.

Atendendo a indefinição diagnóstica da TC foi requisitado o CA 19.9 e ressonância magnética colangio-pancreática (CPRM).

Resultados laboratoriais (18.02.20): leucócitos:

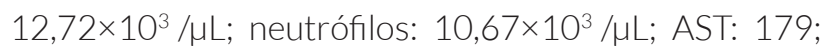
ALT: $183 \mathrm{U} / \mathrm{L}$; bilirrubina total: 10,32 mg/dL; bilirrubina direta: 6,94 mg/dL; GGT: 1165 U/L; FA: 629 U/L; LDH: 308 U/L. CA 19.9: 1955.7.

CPRM: "Marcada dilatação das VBIH e da VBP, com 19 mm. No seu lúmen identifica-se 'sludge' e cálculos, o maior com 17 mm no colédoco terminal, correspondendo à causa obstrutiva. Cístico longo, de implantação medial e baixa. Vesícula biliar sem alterações parietais ou do conteúdo. Sistema ductal pancreático não dilatado" (Fig. 2).

Em 19/02/2020 faz colangiopancreatografia retrógrada endoscópica (CPRE): "VBP muito dilatada com imagens de subtração compatíveis com cálculos. Realizada esfincterotomia endoscópica ampla sem intercorrências. Com recurso a balão de Fogarty extração de pus e abundante quantidade de material litiásico, com vários cálculos, o maior com 17 mm (Fig. 3).

Análises após a CPRE (24/02/2020): leucócitos:

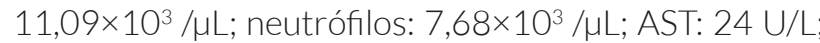
ALT: $43 \mathrm{U} / \mathrm{L}$; bilirrubina total: 2,34 mg/dL; bilirrubina direta: 1,7 mg/dL; GGT: 468 U/L; FA: 329 U/L; CA 19.9: 576.6.

Em 26/02/20: leucócitos: 8,03×1033; neutrófilos: 5,28×103; AST: $44 \mathrm{U} / \mathrm{L}$; ALT: 57; bilirrubina total: 2,09 mg/dL; bilirrubina direta: 1,35 mg/dL; GGT: 277 U/L; FA: $281 \mathrm{U} / \mathrm{L} ;$ CA 19.9: 277.1.

\section{DISCUSSÃO}

Após resolução da colestase (extração do cálculo por CPRE) a doente apresentou uma descida drástica do CA 19.9, que acompanhou a descida de todos os outros valores associados ao padrão colestático (fosfatase alcalina, Gama GT e bilirrubina total). Este fenómeno, associado ao estudo imagiológico (CPRM) e endoscópico permite-nos concluir que a coledocolitíase era a causa da elevação deste antigénio.

Na admissão deste paciente a inexistência de ecografia no Serviço de Urgência, levou a que o clínico assistente optasse pela realização de uma TC (em telemedicina), que viria a condicionar, toda uma estratégia diagnóstica, encarecendo o custo para o paciente, atrasando o diagnóstico e terapêutica do mesmo.

\section{CONCLUSÃO}

Níveis elevados de CA 19.9, não indicam necessariamente a presença de malignidade de uma forma absoluta, e não devem ser utilizados como método único para a diferenciação entre doenças benignas e malignas.

Salces et a ${ }^{10}$ sugerem que a utilidade do nível sérico deste antigénio reside, principalmente, na avaliação do grau de progressão da doença maligna, já diagnosticada, na decisão da radicalidade do seu tratamento e na deteção de uma eventual recidiva.

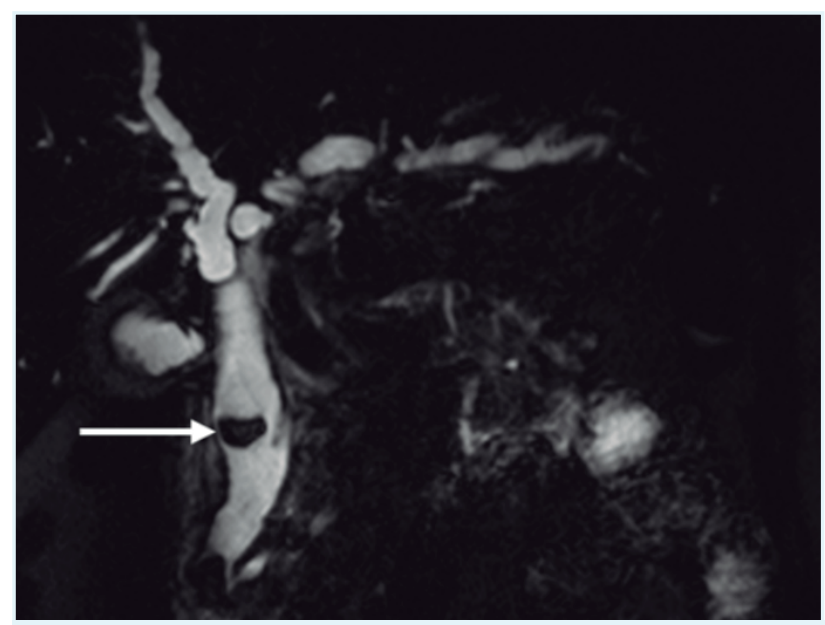

FIGURA 2. CPRM: Coledocolitíase.

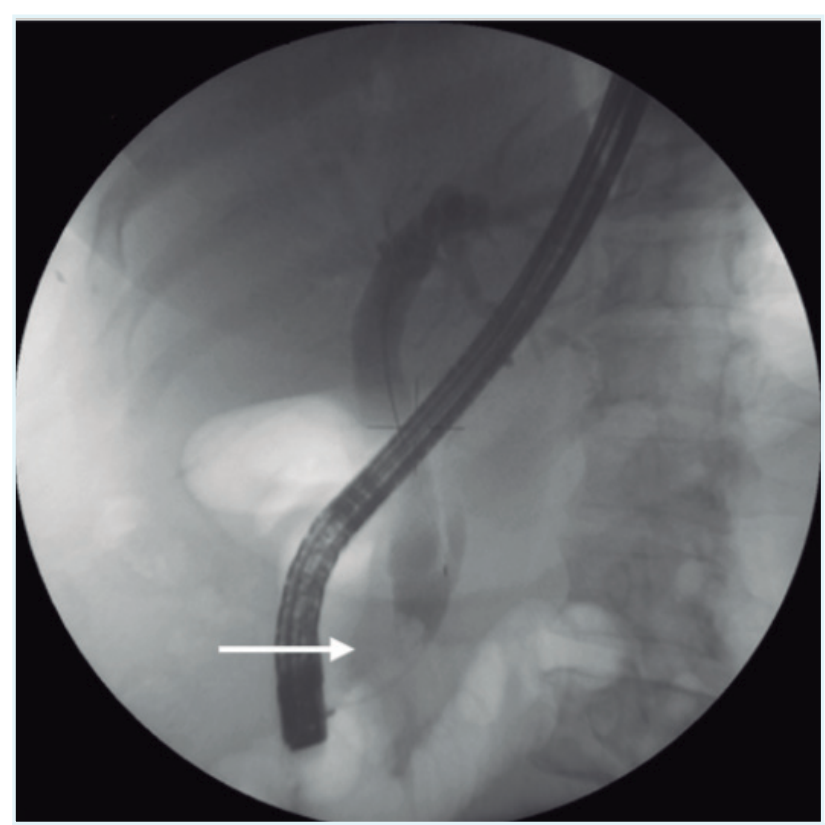

FIGURA 3. CPRE: Dilatação das vias biliares e o cálculo maior. 


\section{RESPONSABILIDADES ÉTICAS}

CONFLITOS DE INTERESSE: Os autores declaram a inexistência de conflitos de interesse na realização do presente trabalho.

FONTES DE FINANCIAMENTO: Não existiram fontes externas de financiamento para a realização deste artigo.

CONFIDENCIALIDADE DOS DADOS: Os autores declaram ter seguido os protocolos da sua instituição acerca da publicação dos dados de doentes.

CONSENTIMENTO: Consentimento do doente para publicação obtido.

PROVENIÊNCIA E REVISÃO POR PARES: Não comissionado; revisão externa por pares.

\section{ETHICAL DISCLOSURES}

CONFLICTS OF INTEREST: The authors have no conflicts of interest to declare.

FINANCING SUPPORT: This work has not received any contribution, grant or scholarship.

CONFIDENTIALITY OF DATA: The authors declare that they have followed the protocols of their work center on the publication of data from patients.

PATIENT CONSENT: Consent for publication was obtained.

PROVENANCE AND PEER REVIEW: Not commissioned; externally peer reviewed.

\section{REFERÊNCIAS}

1. Tsen A, Barbara M, Rosenkranz L. Dilemma of elevated CA 19-9 in biliary pathology. Pancreatology. 2018;18:862-7. doi: 10.1016/j.pan.2018.09.004.

2. Mann DV, Edwards R, Ho S, Lau WY, Glazer G. Elevated tumour marker CA19-9: Clinical interpretation and influence of obstructive jaundice. Eur J Surg Oncol. 2000;26:474-9. doi: 10.1053/ejso.1999.0925.

3. Suzuki K. Elevation of serum and urinary carbohydrate antigen 19-9 in benign hydronephrosis. Int J Urol. 2007;14:668-9. doi: 10.1111/j.1442-2042.2007.01754.x.

4. Steinberg W. The clinical utility of the CA 19-9 tumor-associated antigen. Am J Gastroenterol. 1990;85:350-5.

5. Mimidis K, Anagnostoulis S, lakovidis C, Argyropoulou P. Remarkably elevated serum levels of carbohydrate antigen 19-9 in cystic duct and common bile duct lithiasis. J Gastrointestin Liver Dis. 2008;17:111-2.

6. Sheen-Chen SM, Sun CK, Liu YW, Eng HL, Ko SF, Kuo CH. Extremely elevated CA19-9 in acute cholangitis. Dig Dis Sci. 2007:52:3140-2. doi: 10.1007/s10620-006-9164-7.

7. Kim BJ, Lee KT, Moon TG, Kang P, Lee JK, Kim JJ, et al. How do we interpret an elevated carbohydrate antigen 19-9 level in asymptomatic subjects? Dig Liver Dis. 2009;41:364-9. doi: 10.1016/j.dld.2008.12.094.
8. Ntaios G, Hatzitolios A, Chatzinikolaou A, Karalazou P, Savopoulos C, Karamouzis M, et al. An audit of tumour marker utilization in Greece. Eur J Intern Med. 2009;20:e66-9. doi: 10.1016/j.ejim.2008.07.026.

9. Wang X, Qi X, Li H, Shao X, Guo X. An extremely increased CA19-9 level due to common bile duct stone: a case report. AME Med J. 2017;2:18-18. doi: 10.21037/amj.2017.02.02.

10. Salces I, Vegh I, Rodríguez-Muñoz S, Colina F, Pérez A, Soto S, et al. Tissue CA-19.9 content in colorectal adenomas and its value in the assessment of dysplasia. Rev Esp Enferm Dig. 2004;96:246-54. doi: 10.4321/s113001082004000400003. 